\title{
Effects of Different Backing Materials of Hybrid Rapid Tooling on the Demolding Time in the Hot Embossing Process
}

\author{
Chil-Chyuan KUO*, Teng-Sheng CHIANG
}

\author{
Department of Mechanical Engineering, Ming Chi University of Technology No. 84, Gungjuan Road, New Taipei City \\ 243, Taiwan \\ crossref http://dx.doi.org/10.5755/j01.ms.24.3.13897
}

Received 29 December 2015; accepted 03 June 2016

\begin{abstract}
Fresnel lenses are becoming more and more important because they are widely used as optical elements for concentrating solar power. Micro-hot embossing is a promising approach to fabricate Fresnel lenses. Precision optical elements must be more quickly and cheaply introduced to the market due to the pressure of global competition. The thermal conductivity of Aluminum (Al)-filled epoxy resins is lower than that of conventional mold steel materials. This work demonstrates a technique for fabricating hybrid rapid tooling with different backing materials to investigate the demolding efficiency in the hot embossing process. It was found that the $\mathrm{Al}$ was strongly recommended as backing material for fabricating hybrid rapid tooling due to cost, demolding time efficiency and dimensional accuracy of the embossed parts. Demolding efficiencies for the hot embossing mold with backing materials of copper, aluminum and steel about $78 \%, 68 \%$ and $50 \%$ can be enhanced compared to that of the conventional rapid tooling. The replication rate exceeding $96 \%$ in the hot embossing mold manufacturing process can be reached. The transcription rate exceeding $93 \%$ in the hot embossing process can be obtained.

Keywords: hot embossing, Fresnel lenses, demolding efficiencies, backing materials.
\end{abstract}

\section{INTRODUCTION}

The precision mold and die industry continued to suffer pressure due to both time and expense for manufacturing a mold or die are two main issues in the new product development phase. To solve this issue, additive manufacturing (AM) [1] and rapid tooling technique (RTT) [2-4] was proposed to reduce the manufacturing cost and manufacturing time to market. The physical prototypes could be fabricated swiftly by AM technique compared to long lead times taken by conventional machining. Rapid tooling is capable of replacing conventional mold making to reduce manufacturing cost and development time to market [5]. Direct RTT has played important role in the new product development phase [6]. Wang et al. [7] demonstrated an automatic method to design the conformal cooling circuits used for rapid tooling. Iftikhar et al. [8] developed an innovative turbine blade by using RTT. Yang and Hannul [9] used a precision spray forming to fabricate a rapid tooling. Nandi et al. [10] proposed a new composite mold material to enhance the solidification efficiency in the soft tooling process. Gill and Kaplas [11] proposed a rapid casting technology to fabricate a rapid tooling.

Mohan and Kanny [12] employed the recycled epoxy as reinforcement in an epoxy composite. In general, the Alfilled epoxy resins mold is used as the tentative mold for pilot runs due to it own good mechanical properties and high temperature resistance [13]. However, the demolding time in the hot embossing process is longer due to the poor thermal conductivity of the Al-filled epoxy resin compared to metal. Therefore, enhancing the efficiency of demolding

\footnotetext{
* Corresponding author. Tel.: +8862 29089899; fax: +886229063269.

E-mail address: jacksonk@mail.mcut.edu.tw (C.C. Kuo)
}

time during the hot embossing in the development phase of a new optical element is an important issue. In this study, hot embossing molds with different backing materials were fabricated to investigate the demolding efficiency in the hot embossing process. The effects of different backing materials on the demolding time are investigated. The replication rates of the four hot embossing molds were examined. The Fresnel lens was fabricated using hot embossing molding. The transcription rates of the embossed parts were also investigated using an optical microscopy.

\section{EXPERIMENT}

The Al-filled epoxy resins (174 A, Jasdi Chemicals) and silicone rubber (KE-1310ST, Shin Etsu) were chosen as mold making materials. The master model is a Fresnel lens with dimensions of $3 \mathrm{~cm}$ in length and $3 \mathrm{~cm}$ in width. The detailed manufacturing processes of hot embossing mold are described in the previous study [14]. The copper (1100, Poki Metal), steel (Nak-80, Daido Steel) and Al (6061, Nikko Metals) were first machined as backing materials to fabricate hybrid rapid tooling using a universal milling machine. The backing material thickness is $15 \mathrm{~mm}$. The vacuum machine was used to eliminate air bubbles from the molding materials [15]. Firstly, the positive silicone rubber mold was manufactured by pouring the mixed silicone rubber over the master model. The master model was not adversely affected due to no heat was generated during the curing process. Silicone rubber was mixed with a curing agent with a 10:1 mass ratio. Spraying release agent to the surface of the positive silicone rubber mold is necessary before fabricating the negative rubber mold. The negative rubber mold was then created from a positive silicone rubber mold. Finally, the hot embossing 
mold was created by pouring the mixed epoxy resin composites over the positive silicone rubber mold. The hot embossing mold was then cured in a convection oven (DH400, Deng Yag) to reach the mechanical properties required. After post cure, the fabricated hot embossing mold possesses adequate mechanical strength for hot embossing molding. The replication rates of the four fabricated hot embossing molds and the transcription rates of the embossed Fresnel lenses were analyzed.

Fig. 1. shows the experimental setup for thermal conductivity measurement of different backing materials according to ASTM D5470 [16]. Temperature measurements were made using six K-type thermocouples (C071009-079, Cheng Tay) for calculating thermal conductivity. Note that the $\mathrm{Th}$ and Tc indicate temperatures at the interfaces of cold and hot ends. The dimensions of the test sample are $13 \mathrm{~mm}$ in length and $25 \mathrm{~mm}$ in diameter. A test sample was mounted under load of $360 \mathrm{~N}$ between two Al terminals in order to minimize air gaps between Al terminal and the test sample. The dimensions of the cylinder Al terminal are $30 \mathrm{~mm}$ in length and $25 \mathrm{~mm}$ in diameter. A heat flux of $10 \mathrm{~W}$ was supplied at the hot end. Cooling was performed by water circulating at a rate of $400 \mathrm{cc} / \mathrm{min}$ in the cold end. In order to investigate the demolding time in the hot embossing process, temperature histories of the embossing process were measured using a k-type thermocouple and a data collection system (MRD-8002L, Acqview). The ANSYS Icepak software was used to predict the demolding time in the hot embossing process. A series of experiments were performed to optimize the embossing parameters. The process parameters for hot embossing molding are embossing temperature of $120^{\circ} \mathrm{C}$, embossing force of $900 \mathrm{~N}$, and holding time of $10 \mathrm{~min}$. The home-made hot embossing machine was used for hot embossing molding. The $0.8 \mathrm{~mm}$ thick polymethylmethacrylate (PMMA) films (MH, Meihan Shinku Kogyo) were used as molding material. The replication rates of the four fabricated hot embossing molds and the transcription rates of the embossed parts were examined using an optical microscopy (M835, Microtech).

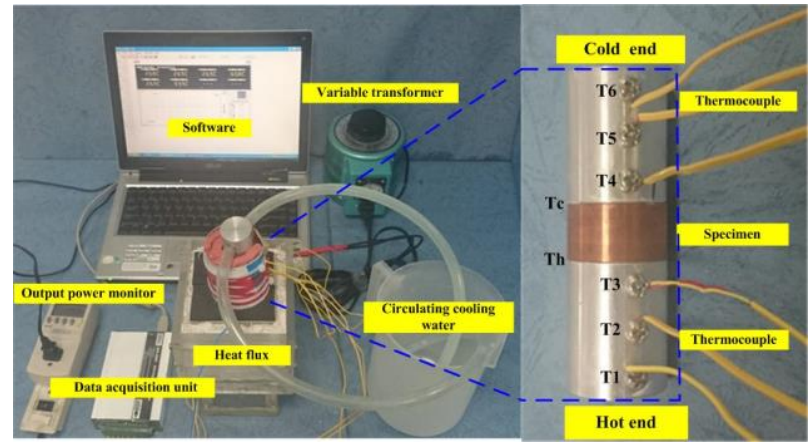

Fig. 1. Experimental setup for thermal conductivity measurement of different backing materials. The temperature histories were recorded by six thermocouples referred to as $T 1, T 2$, T3, T4, T5, and T6. Temperatures $T \mathrm{~h}$ and $T \mathrm{c}$ can be determined by the extrapolation method form the temperature values measured

The solid model preparation was carried out with the software Solidworks. Hexagonal 3D quadratic stress elements, SOLID 95, were used for mashing the part [10].
The Young's modulus and the Poisson's ratio of the epoxy resin were determined from the results of mechanical testing using a universal testing machine (Insight $5 \mathrm{SL}$, MTS system Inc.).The Young's modulus for the new epoxy resins and recycled epoxy resins are about 9.9 GPa and 3.7 GPa, respectively. The Poisson's ratio for the new epoxy resins and recycled epoxy resins are about 0.32 and 0.27 , respectively. Boundary conditions were applied to the embossed areas. The applied load is about $650 \mathrm{~N}$. Maximum stresses of a large-area hot embossing mold were investigated by finite element method using ANSYS software.

\section{RESULTS AND DISCUSSION}

Fig. 2. presents the thermal distributions over the length of Al-filled epoxy resins, $\mathrm{Al}, \mathrm{Cu}$, and steel. Temperature readings were recorded every 30 minutes. The thermal conductivity can be determined when the temperature reaches the steady-state conditions. For the sample of Al-filled epoxy resins, the thermal conductivity slightly goes down from $2.73 \mathrm{~W} / \mathrm{m}-\mathrm{K}$ to $1.94 \mathrm{~W} / \mathrm{m}-\mathrm{K}$ as the measurement time arises and saturates at thermal conductivity of $1.94 \mathrm{~W} / \mathrm{m}-\mathrm{K}$. The same phenomena are observed for $\mathrm{Al}, \mathrm{Cu}$, and steel. Thus, the calculated thermal conductivity values for Al-filled epoxy resins, $\mathrm{Al}, \mathrm{Cu}$, and steel are estimated to be $1.94 \mathrm{~W} / \mathrm{m}-\mathrm{K}, 162.23 \mathrm{~W} / \mathrm{m}-\mathrm{K}$, $397.45 \mathrm{~W} / \mathrm{m}-\mathrm{K}$ and $47.04 \mathrm{~W} / \mathrm{m}-\mathrm{K}$, respectively. To understand the experimental error of the thermal conductivity measured, a series of five tests were carried out on each sample. All the experimental results are shown in Fig. 3. These results show that the reproducibility of the results is in agreement with previous measurement. It is worth pointing out that the maximum standard variation of the thermal conductivity of $\mathrm{Cu}$ is estimated to be $8.46 \mathrm{~W} / \mathrm{m}-\mathrm{K}$.

The ANSYS Icepak software was used to predict the transient heat transfer of the hot embossing process [17]. Fig. 4. illustrates the temperature as a function of predicted demolding time in the hot embossing process using the ANSYS Icepak software. The predicted demolding time can be determined when the temperature of mold surface reached the demolding temperature. As can be seen, the predicted demolding times for the hot embossing molds with backing materials of Al-filled epoxy resins, $\mathrm{Al}, \mathrm{Cu}$, and steel are $130 \mathrm{~min}, 25 \mathrm{~min}, 20 \mathrm{~min}$, and $55 \mathrm{~min}$, respectively. To obtain the actual demolding time, Al-filled epoxy resins, $\mathrm{Al}, \mathrm{Cu}$, and steel were employed as backing materials to fabricate embossing molds for hot embossing molding, as shown in Fig. 5.

The embossing molds exhibit superior dimensional accuracy due to very little shrinkage during the curing process. The width and depth of a master model are $67 \mu \mathrm{m}$ and $400 \mu \mathrm{m}$, respectively. The averages of width and depth for the hot embossing molds with backing materials of steel are $65 \mu \mathrm{m}$ and $397 \mu \mathrm{m}$, respectively. Hence, the transcription rates in the width and depth are $97 \%$ and $96.7 \%$, respectively. The averages of the width and depth for the hot embossing molds with backing materials of $\mathrm{Al}$ are $66 \mu \mathrm{m}$ and $398 \mu \mathrm{m}$, respectively. Hence, the transcription rates in the width and depth are $98.5 \%$ and $99.5 \%$, respectively. 

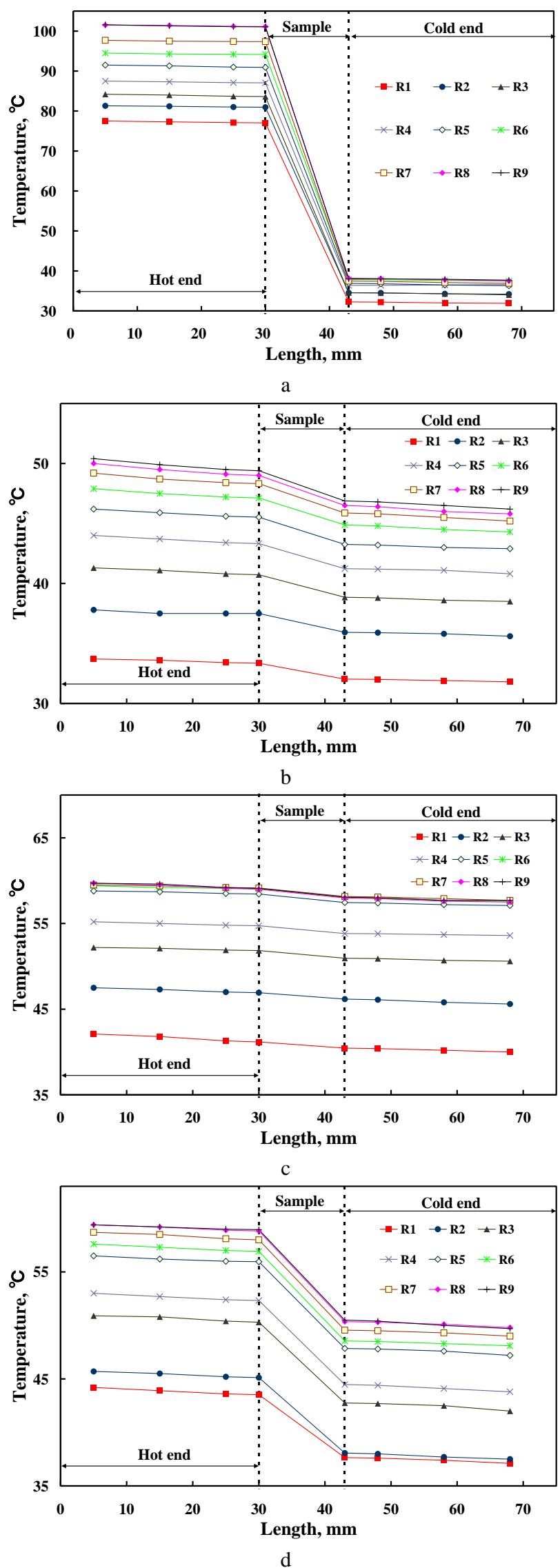

Fig. 2. Thermal distributions over the length of: a-Al-filled epoxy resins; $\mathrm{b}-\mathrm{Al} ; \mathrm{c}-\mathrm{Cu} ; \mathrm{d}-$ steel

The averages of the width and depth for the hot embossing molds with backing material of $\mathrm{Cu}$ are $65 \mu \mathrm{m}$ and $397 \mu \mathrm{m}$, respectively.

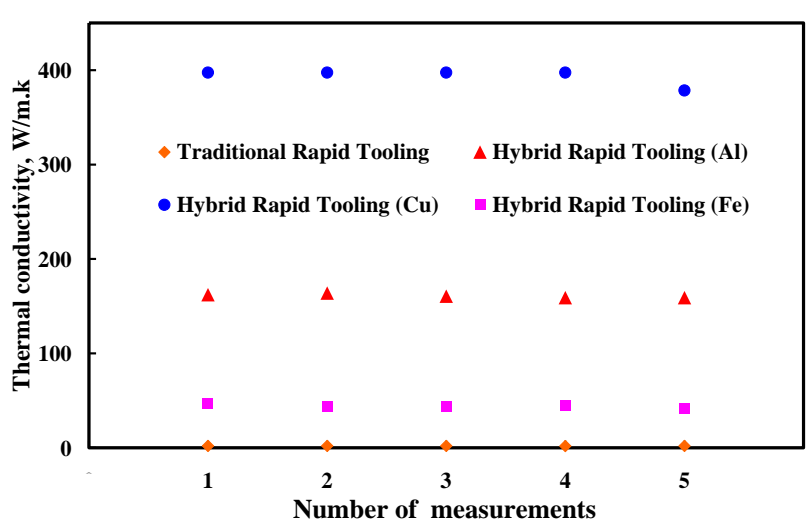

Fig. 3. Variations of thermal conductivity measurement for Alfilled epoxy resins, $\mathrm{Al}, \mathrm{Cu}$, and steel

Hence, the transcription rates in the width and depth are $97 \%$ and $99.2 \%$, respectively. The averages of the width and depth for the conventional hot embossing molds are $66 \mu \mathrm{m}$ and $397 \mu \mathrm{m}$, respectively. The transcription rates in the width and depth are $98.5 \%$ and $99.2 \%$, respectively. Thus, the replication rate of the fabricated embossing molds exceeding $96 \%$ can be obtained.

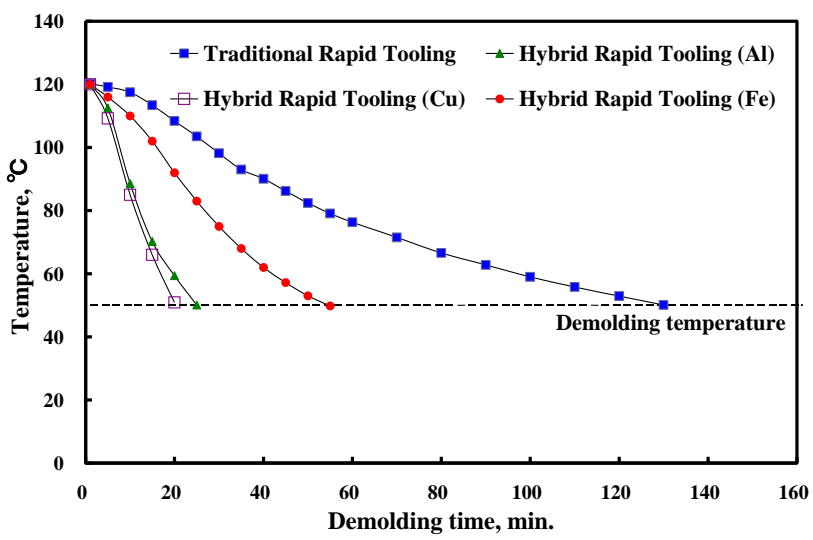

Fig. 4. Temperature as a function of predicted demolding time in the hot embossing process using the ANSYS Icepak software

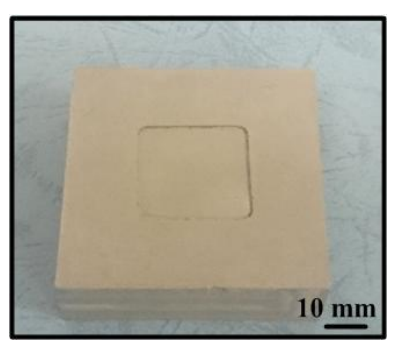

$\mathrm{a}$

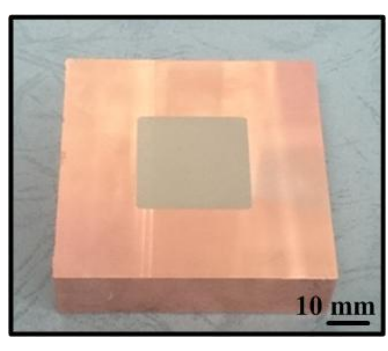

c

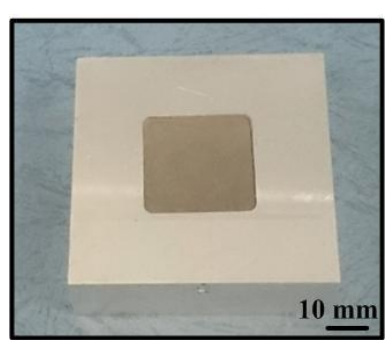

b

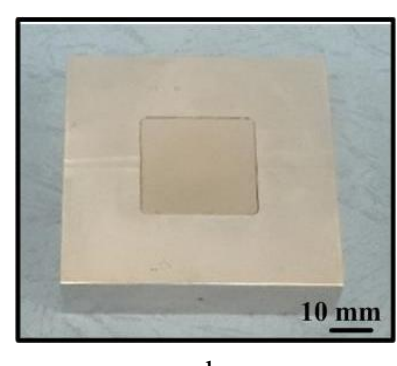

d
Fig. 5. Hot embossing molds with backing materials of: a-Alfilled epoxy resins; $\mathrm{b}-\mathrm{Al} ; \mathrm{c}-\mathrm{Cu} ; \mathrm{d}-$ steel 
Hot embossing is a promising method to fabricate Fresnel lens to be used as optical elements for concentrating solar power. Long cycle time is related to the time interval from the embossing temperature to demolding temperature. To enhance the efficiencies of hot embossing process, shortening this time interval is critical. Fig. 6. shows the temperature as a function of the actual demolding time in the hot embossing process. The actual demolding times for the hot embossing molds with backing materials of $\mathrm{Al}$-filled epoxy resins, $\mathrm{Al}, \mathrm{Cu}$, and steel are $140 \mathrm{~min}, 45 \mathrm{~min}, 30 \mathrm{~min}$, and $70 \mathrm{~min}$, respectively. To understand the experimental error of the actual demolding time, a series of ten tests were carried out. All the experimental results are shown in Fig. 7. showing that the reproducibility of the results is in agreement with previous measurement. The mean actual demolding times for the hot embossing molds with backing materials of Al-filled epoxy resins, $\mathrm{Al}, \mathrm{Cu}$, and steel are $140.8 \mathrm{~min}, 45.1 \mathrm{~min}, 30.4 \mathrm{~min}$, and $70.6 \mathrm{~min}$, respectively. It was found that the trend of demolding efficiency from experimental data was in good agreement with those predicted by numerical simulations. The maximum standard variation of the demolding time of steel is estimated to be $1.6 \mathrm{~min}$. Thus, the demolding time efficiencies for hot embossing mold with backing materials of copper, aluminum and steel about $78 \%, 68 \%$ and $50 \%$ can be enhanced compared to that of the conventional rapid tooling. The result meets the concept of fast fabrication $[18,19]$.

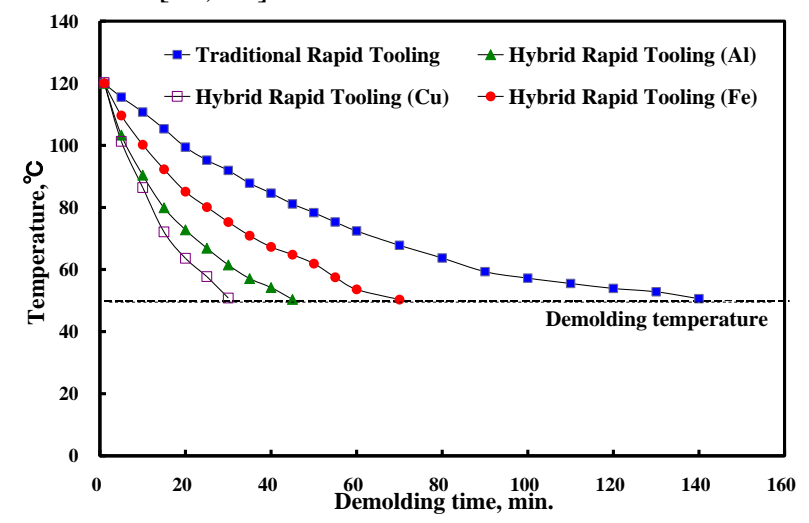

Fig. 6.Temperature as a function of the actual demolding time in the hot embossing process. The actual demolding time can be determined when the temperature of mold surface reached the demolding temperature

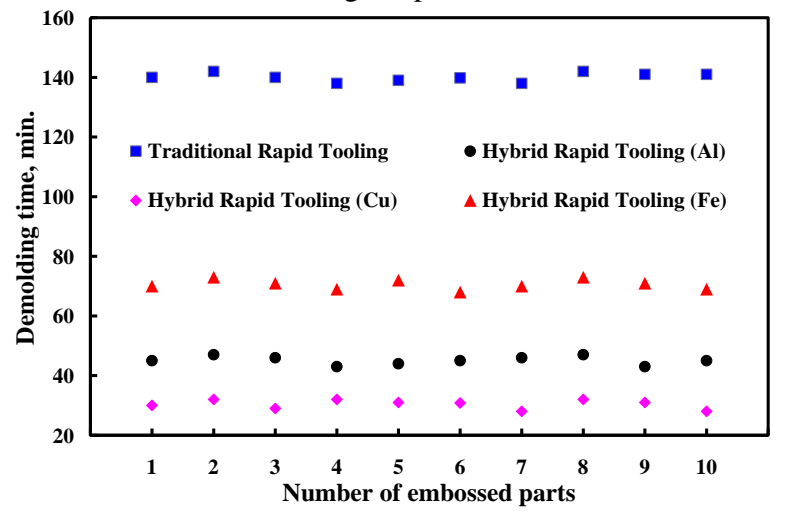

Fig. 7. Variation of actual demolding time in the hot embossing process

Fig. 8 and Fig. 9 shows the dimensional accuracy of the Fresnel lens fabricated by the hot embossing molds with different backing materials. The dimension variations of the width can be controlled from $-4 \mu \mathrm{m}$ to $-1 \mu \mathrm{m}$. Besides, the dimension variations of the depth can be controlled from $-11 \mu \mathrm{m}$ to $-1 \mu \mathrm{m}$. It must be mentioned that the dimensional variations of the Fresnel lens fabricated by the hot embossing molds with backing material of $\mathrm{Cu}$ are the largest due to shrinkage. One possible reason to cause this result is rapid heat transfer speed showing that the front Fresnel lenses solidify rapidly. Besides, the cost of $\mathrm{Cu}$ is higher than $\mathrm{Al}$. This means that $\mathrm{Al}$ seems to be a good candidate as a backing material for fabricating hot embossing replication master [20] in terms of demolding efficiency and dimensional accuracy of the Fresnel lens. The transcription rates for hot embossing molds with backing materials of Al-filled epoxy resins, $\mathrm{Al}, \mathrm{Cu}$, and steel are about $97 \%, 97 \%, 93 \%$, and $96 \%$, respectively. Thus, the transcription rate exceeding $93 \%$ can be obtained under the optimum embossing conditions. This means that precision diffractive optical elements can be fabricated by gas-assisted hot embossing molding [21], although the shrinkage of the PMMA is about $0.2-0.6 \%$. The proposed method for fabricating hot embossing mold needs no expensive equipment. Thus, the proposed method exhibits simplicity and economic due to without using the silicon-based micro-machining [22], ultrafast femtosecond laser micro-machining [23], microelectro discharge machining [24], and electrochemical micro-machining [25]. Unfortunately, the lifetime of hybrid rapid tooling is limited because the mold surface is made from Al-filled epoxy resins.

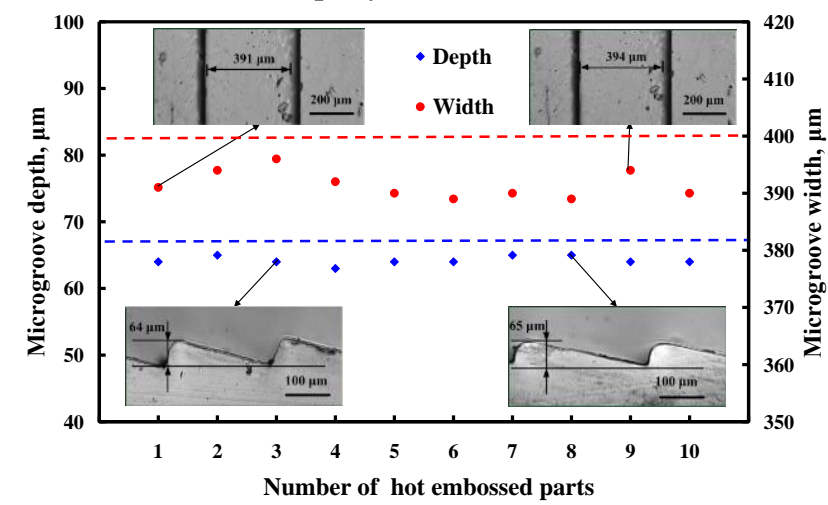

a

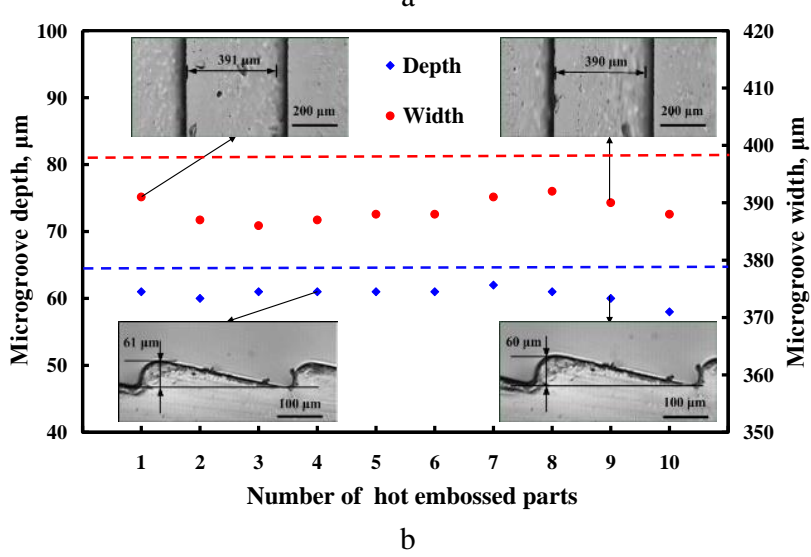

Fig. 8. Dimensional accuracy of the Fresnel lens fabricated by the hot embossing molds with backing materials of: $\mathrm{a}-\mathrm{Al}-$ filled epoxy resins; $b-A l$. Dashed lines show the dimensions of width and depth of hot embossing mold 


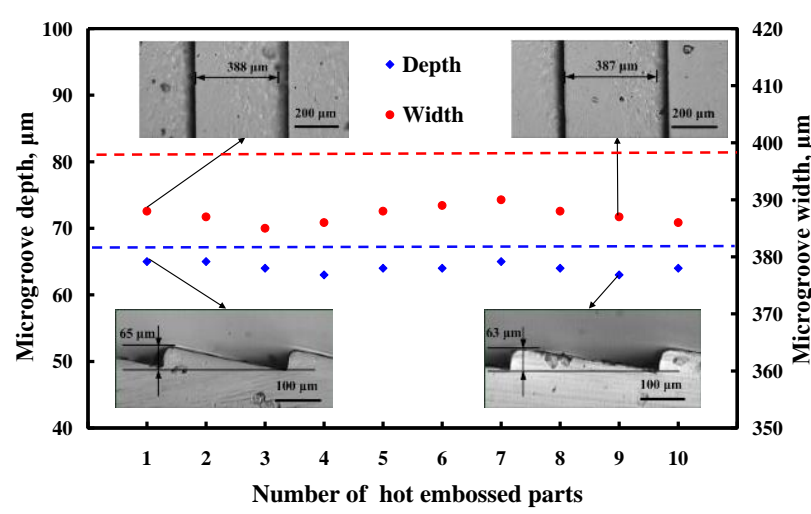

a

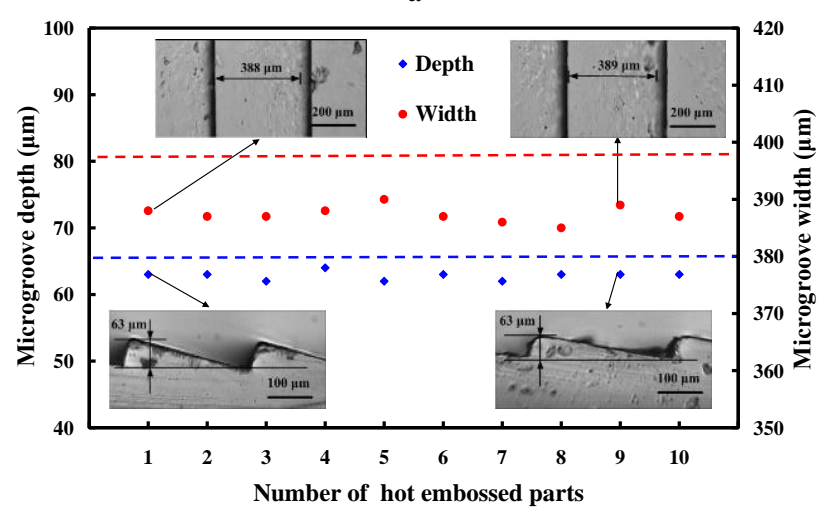

b

Fig. 9. Dimensional accuracy of the Fresnel lens fabricated by the hot embossing molds with backing materials of: $\mathrm{a}-\mathrm{Cu}$; $\mathrm{b}$-steel. Dashed lines show the dimensions of width and depth of hot embossing mold

Further investigation on lengthening the mold life of hot embossing mold is required. In addition, optimization of the thickness of hot embossing molds is required by using ANSYS simulation software [26-29].

\section{CONCLUSIONS}

The aim of this study was to present four hybrid embossing molds with different backing materials. The thermal conductivities of four different backing materials have been measured experimentally. The effects of different backing materials on demolding time in the hot embossing process have been investigated. Based on the results discussed in this study, the following conclusions can be drawn:

1. The results of this study exhibit wide industrial application values because it can accelerate the development speed of a new precision optical element in the research and development phase. The hot embossing mold has the simplicity of the manufacturing process and cost-effective manufacturing cost.

2. Al seems to be a good candidate as a backing material for fabricating hot embossing mold in terms of cost, demolding time efficiency and dimensional accuracy of the embossed parts.

3. The hot embossing mold is rigid enough for short runs of precision optical elements using hot embossing technique.

4. The demolding time efficiencies for the hot embossing mold with backing materials of copper, aluminum and steel approximately $78 \%, 68 \%$ and $50 \%$ can be enhanced.

5. The hot embossing mold can be fabricated without loss in detail. It has been verified that the replication rate exceeding $96 \%$ can be reached.

6. The transcription rate of Fresnel lenses exceeding $93 \%$ of the embossed parts can be obtained under the optimum embossing conditions.

\section{Acknowledgements}

The authors gratefully acknowledge the financial support of the Ministry of Science and Technology of Taiwan under contract no. MOST 103-2221-E-131-012.

\section{REFERENCES}

1. Masood, S.H. Introduction to Advances in Additive Manufacturing and Tooling Comprehensive Materials Processing 10 2014: pp. 1-2.

2. Kuo, C.C., Liao, H.Y. Enhancing the Mechanical Properties of Epoxy Resin Mold by Adding Zirconia Particles Materials and Manufacturing Processes 29 (7) 2014: pp. $840-847$. https://doi.org/10.1080/10426914.2014.912311

3. Kuo, C.C., Hsu, H.J. Development and Application of Hybrid Mold with Microfeatures in Micro-Hot Embossing Materials and Manufacturing Processes 28 (11) 2013: pp. $1203-1208$. https://doi.org/10.1080/10426914.2013.832305

4. Kuo, C.C., Hsu, H.J. Micro-Hot Embossing of Fresnel Lens Using Precision Micro-Featured Mold Materials and Manufacturing Processes 28 (11) 2013: pp. 1228-1233. https://doi.org/10.1080/10426914.2013.811748

5. Kuo, C.C. A Simple and Cost-Effective Method for Fabricating Epoxy-Based Composites Mold Inserts Materials and Manufacturing Processes 27 (4) 2012: pp. $383-388$. https://doi.org/10.1080/10426914.2011.551906

6. Rahmati, S. Direct Rapid Tooling Comprehensive Materials Processing 10 2014: pp. 303-344. https://doi.org/10.1016/B978-0-08-096532-1.01013-X

7. Wang, Y., Yu, K.M., Wang, C.C.L., Zhang, Y. Automatic Design of Conformal Cooling Circuits for Rapid Tooling Computer-Aided Design 43 2011: pp. 1001-1010. https://doi.org/10.1016/j.cad.2011.04.011

8. Iftikhar, A., Khan, M., Alam, K., Jaffery, S.H.I., Ali, L., Ayaz, Y., Khan, A. Turbine Blade Manufacturing Through Rapid Tooling (RT) Process and Its Quality Inspection Materials and Manufacturing Processes 28 (5) 2013: pp. $534-538$. https://doi.org/10.1080/10426914.2012.746698

9. Yang, Y., Hannula, S.P. Development of Precision Spray Forming for Rapid Tooling Materials Science and Engineering: A 477 (1-2) 2008: pp. 63-68. https://doi.org/10.1016/j.msea.2007.09.080

10. Nandi, A.K., Deb, K., Datta, S. Genetic Algorithm-Based Design and Development of Particle-Reinforced Silicone Rubber for Soft Tooling Process Materials and Manufacturing Processes 28 (7) 2013: pp. 753-760. https://doi.org/10.1080/10426914.2013.773022

11. Gill, S.S., Kaplas, M. Comparative Study of 3D Printing Technologies for Rapid Casting of Aluminium Alloy Materials and Manufacturing Processes 24 (12) 2009: pp. $1405-1411$. 
https://doi.org/10.1080/10426910902997571

12. Mohan, T.P., Kanny, K. Reuse of Cured Epoxy as a Reinforcement in an Epoxy Composite Polymer Engineering and Science 53 (9) 2013: pp. 1839-1844. https://doi.org/10.1002/pen.23444

13. Pramanik, M., Fowler, E.W., Rawlins, J.W. Another Look at Epoxy Thermosets Correlating Structure with Mechanical Properties Polymer Engineering and Science 54 (9) 2014: pp. 1990-2004. https://doi.org/10.1002/pen.23444

14. Kuo, C.C., Wang, Y.J. Development of a Micro-Hot Embossing Mold with High Replication Fidelity Using Surface Modification Materials and Manufacturing Processes 29 (9) 2014: pp. 1101-1110. https://doi.org/10.1080/10426914.2014.912312

15. Kuo, C.C., Lai, M.Y. Development of an Automatic Vacuum Degassing System and Parameters Optimization for Degassing Process Indian Journal of Engineering and Materials Sciences 18 (6) 2011: pp. 405-410. http://nopr.niscair.res.in/handle/123456789/13596

16. Azeem, S., Zain-ul-Abdein, M. Investigation of Thermal Conductivity Enhancement in Bakelite-Graphite Particulate Filled Polymeric Composite International Journal of Engineering Science 52 (6) 2012: pp. 30-40. https://doi.org/10.1016/j.ijengsci.2011.12.002

17. Hill, R.D., Conner, J.M. Transient Heat Transfer Model of Machine Gun Barrels Materials and Manufacturing Processes 27 (83) 2012: pp. 840-845. https://doi.org/10.1080/10426914.2011.648694

18. Lin, K.Y., Liu, S.J. Fast Fabrication of Microfeatured Plastic Diffusers Using IR-Assisted Injection Molding Materials and Manufacturing Processes 28 (1) 2012: pp. 19-23. https://doi.org/10.1080/10426914.2012.677915

19. Azouz, A.B., Murphy, S., Karazi, S., Vázquez, M., Brabazon, D. Fast Fabrication Process of Microfluidic Devices Based on Cyclic Olefin Copolymer Materials and Manufacturing Processes 29 (2) 2014: pp. 93-99. https://doi.org/10.1080/10426914.2013.811739

20. Ali, M.Y., Mohammad, A.S. Effect of Conventional EDM Parameters on the Micromachined Surface Roughness AND Fabrication of a Hot Embossing Master Microtool Materials and Manufacturing Processes 24 (4) 2009: pp. $454-458$.

https://doi.org/10.1080/10426910802714373
21. Hocheng, H., Wen, T.T., Yang, S.Y. Replication of Microlens Arrays by Gas-Assisted Hot Embossing Materials and Manufacturing Processes 23 (3) 2008: pp. $261-268$. https://doi.org/10.1080/10426910701860830

22. Lin, Y.C., Hocheng, H., Fang, W.L., Chen, R. Fabrication and Fatigue Testing of an Electrostatically Driven Microcantilever Beam Materials and Manufacturing Processes 21 (1) 2006: pp. 75-80. https://doi.org/10.1080/AMP-20006597

23. Uppal, N., Shiakolas, P.S., Priya, S. Micromachining of PZT Using Ultrafast Femtosecond Laser Materials and Manufacturing Processes 32 (3-4) 2005: pp. 67-77. https://doi.org/10.1080/07315170500311465

24. Sheu, D.Y., Cheng, C.C. Micro Three-Dimensional Cavities Tools Fabrication on PCD by U-EDM Scanning Process Materials and Manufacturing Processes 28 (1) 2012: pp. $42-47$. https://doi.org/10.1080/10426914.2012.718468

25. Malapati, M., Bhattacharyya, B. Investigation into Electrochemical Micromachining Process during MicroChannel Generation Materials and Manufacturing Processes 26 (8) 2011: pp. 1019-1027. https://doi.org/10.1080/10426914.2010.525575

26. Quan, H.T., Henri, C., Zhengkun, F., Thien, M.D. Analysis of the Asymmetrical Roll Bending Process Through Dynamic FE Simulations and Experimental Study The International Journal of Advanced Manufacturing Technology 75 (5) 2014: pp. $1233-1244$. https://doi.org/10.1007/s00170-014-6176-x

27. Elango, N., Marappan, R. Analysis on the Fundamental Deformation Effect of a Robot Soft Finger and Its Contact Width During Power Grasping The International Journal of Advanced Manufacturing Technology 52 (5) 2011: pp. $794-804$. https://doi.org/10.1007/s00170-010-2747-7

28. Wenji, X., Xin, L., Jing, S., Lin, Z. Finite Element Simulation and Experimental Research on Electric Hot Machining The International Journal of Advanced Manufacturing Technology 66 (1) 2013: pp. 407-415. https://doi.org/10.1007/s00170-012-4335-5

29. Martínez-Figueroa, J., Rubio-Gonzalez, C., VelascoReyes, F. Three Point Bending Hopkinson Bar for Fracture Toughness Measurement: A New Approach for Interface Analysis Materialwissenschaft und Werkstofftechnik 46 (4-5) 2015: pp. 505-514.

https://doi.org/10.1002/mawe.201500426 